\title{
Electrosynthesis via Plasma Electrochemistry: Generalist Dynamical Model to Explain Hydrogen Production Induced by a Discharge over Water
}

Andressa Mota-Lima, ${ }^{1 *}$ Jailton Ferreira do Nascimento, ${ }^{2}$ Osvaldo Chiavone-Filho ${ }^{3}$ and Claudio Augusto Oller Nascimento ${ }^{1}$

1 Department of Chemical Engineering, Polytechnic School, University of São Paulo (USP), Avenue Prof. Luciano Gualberto 380, São Paulo-SP, 05508-010, Brazil

2 Centro de Pesquisas e Desenvolvimento Leopoldo Americo Miguez de Mello (CENPES/PETROBRÁS), Avenue Horácio Macedo, 950, Q.7 Ilha do Fundão, Rio de Janeiro-RJ, 21941-915, Brazil

3 Department of Chemical Engineering, Federal University of Rio Grande do Norte (UFRN), Avenue Senador Salgado Filho 3000, Natal-RN, 59066-800, Brazil.

*mota@usp.br

Summary:

\section{Glossary.}

Supplementary data A: Volume of the plasma-induced reactor in liquid phase.

Supplementary data B: Connecting the time evolution of faradaic current during an electrochemical discharge to the rate of electron release to the liquid ( $\left.q_{e}\right)$.

Supplementary data $\boldsymbol{C}$ : Estimation of the plasma-induced source terms of scavenger $\left(q_{s}\right)$. 


\section{Glossary.}

Chemical mechanism: it is the sequence of reactions that describes events with atomic precision and that produces one or more dead products (also known as final products).

Computational modeling: a set of experimental data is modeled when the scientist/operator screens mathematical models (linear, polynomial etc) by means of a method based on linear regression to obtain the best mathematical model in terms of statistical predictability of the experimental variables.

Computational experiment: asking questions to an algorithm instead of to a real life experiment is all about the experiments aided by a computer. If the algorithm bases on a theoretical frame that describes the event properly, several information can be obtained with the computational experiment, normally with more details than does the real life experiments that for practical reason the access to information is unfeasible.

Atmospheric cold plasma: it is a discharge between two highly conductive terminals (normally a metal) connected to a high voltage source when the gases filling the gap are at the same pressure of the earth atmosphere. It might occur that other materials different from gases at room temperature fills part of the space in between the high voltage terminals. Such materials are dielectric materials in either liquid state (water), viscous phase (glass) or solid state (ice).

Electrochemical plasma: atmospheric cold plasma that necessarily has, contacting each other, both the water and the atmospheric-pressure gas in between the terminals of high voltage, forming a sandwich layering structure. In such configuration the model of the article necessarily has to have $q_{e}>0$ but could admit either $q_{s}=0$ or $q_{s}>0$.

Electrochemical plasma (type I-Contactless discharge)/ discharge over water: it is said to be a contactless electrochemical plasma because there is a visible opened section from the equivalent electrical circuit perspective, being the gap between the metallic tip and the water surface filled with static (or quasi static) gas. When the discharge develops, this section closes by the plasma that has good electrical 
conduction. In such configuration the model of the article necessarily has to have $q_{e}$ $>0$ but could admit either $q_{s}=0$ or $q_{s}>0$.

Electrochemical plasma (type I-Contactless discharge)/ discharge over water with jet effect: it is said to be a contactless plasma with jet effect because the metallic tip is hollow, allowing a flow of gases from inside. In this configuration, the gap between the metallic tip and the water surface fills with a high mechanical flow of ionized species, promoting the jet effect of the plasma. In such configuration the model of the article necessarily has to have $q_{e}>0$ but could admit either $q_{s}=0$ or $q_{s}>0$.

Electrochemical plasma (type II-Contac discharge)/ discharge in water: it is said to be a contact electrochemical plasma because the metallic tip is immersed inside the liquid water. Initially the equivalent circuit is closed and connected to the high voltage source, whereas gases are continuously formed by means of conventional electrochemical electrolysis on the solid/liquid contact. Once sufficiently large volume of gases to cover substantially the contact solid/liquid is formed, the discharge develops in between the metallic tip and the inner surface of the bubble where there is a gas/liquid contact. In such configuration the model of the article necessarily has to have $q_{e}>0$ but only admit scavenger derived from the humid discharge if using a salt for supporting electrolyte, thus $q_{s}=\{$ radical $O H$,$\} and q_{O H}>0$.

Theoretical frame: set of concepts normally, but not necessarily, expressed in the mathematical language that helps to understand a physical chemical event.

Torch-like plasma: it is an atmospheric cold plasma having exclusively gases under permanent flow in between the terminals of high voltage, being the upstream flow rich in plasma-based species. It happens that the effluents of torch-like plasma could be bring close to the water surface, contacting it. In such configuration the model of the article has to have $q_{e}=0$ and $q_{s}>0$, necessarily. 
Supplementary data A: Volume of the plasma-induced reactor in liquid phase.

Table S1: Physical dimensions for the nano-reactor.

\begin{tabular}{|c|l|c|}
\hline $\begin{array}{c}\text { Extracted from } \\
\text { Rumbach et al. } \\
2015(2)\end{array}$ & Electron penetration, (P)/m & $12.0010^{-9}$ \\
\hline $\begin{array}{c}\text { Contact area for } \\
\text { PLI }\end{array}$ & {$\left[\pi \frac{\left(\boldsymbol{D}_{\boldsymbol{i}}\right)^{2}}{4}\right] / \mathrm{m}^{2}$} & $1.9610^{-7}$ \\
\hline $\begin{array}{c}\text { Volume of the } \\
\text { nano-reactor }\end{array}$ & $\begin{array}{c}\text { Volume (V) of the Nanoreactor / L } \\
\boldsymbol{P} \times\left[\pi \frac{\left(\boldsymbol{D}_{\boldsymbol{i}}\right)^{2}}{4}\right] \text { at STP }\end{array}$ & $2.3610^{-9}$ \\
\hline
\end{tabular}

Supplementary data B: Connecting the time evolution of faradaic current during an electrochemical discharge to the rate of electron release to the liquid $\left(q_{e}\right)$.

Table S2: Electrical characteristics for the discharge powered by pulse-modulated dc voltage from Urabe et al. Plasma Sources Sci. Technol., vol. 25, no. 4, 2016 (1).

\begin{tabular}{|c|c|c|c|}
\hline \multicolumn{3}{|c|}{ Standard SI units } & As gathered from the \\
\hline \multirow{5}{*}{$\begin{array}{l}\text { Extracted from } \\
\text { Urabe et } \\
\text { al.2016 (1) }\end{array}$} & Nozzle Inner diameter $\left(\mathbf{D}_{\mathbf{i}}\right) / \mathrm{m}$ & $0.5010^{-3}$ & $0.5 \mathrm{~mm}$ \\
\hline & Period of the pulsed voltage $\left(\boldsymbol{t}_{\boldsymbol{p}}\right) / \mathrm{s}$ & $2.0010^{-3}$ & $2 \mathrm{~ms}$ \\
\hline & Duty Cycle & $50 \%$ & \\
\hline & Period for the closed circuit $\left(\boldsymbol{t}_{\boldsymbol{o n}}\right) / \mathrm{s}$ & $1.0010^{-3}$ & $1 \mathrm{~ms}$ \\
\hline & $J / A$ & $150.0010^{-3}$ & $150 \mathrm{~mA}$ \\
\hline \multirow{2}{*}{$\begin{array}{l}\text { Estimations } \\
\text { from This } \\
\text { work }\end{array}$} & $\begin{array}{l}\text { Release rate of ballistic electrons / mol s } \\
\qquad q_{e} \equiv \frac{\Delta n_{e}}{\Delta t}=\frac{J}{96485}\end{array}$ & $1,555.0010^{-9}$ & $\mathrm{X}$ \\
\hline & $\begin{array}{l}\text { Total number of electrons released per } \\
\text { discharge/ mol } \\
\qquad q_{e} \times t_{\text {on }}\end{array}$ & $1.5510^{-9}$ & $\mathrm{X}$ \\
\hline
\end{tabular}


Supplementary data $C$ : Estimation of the plasma-induced source terms of scavenger $\left(q_{s}\right)$.

Based on the work of Gorbanev et al. (3), it is possible to estimate the release rate of either $\bullet \mathrm{OH}$ or $\mathrm{H}_{2} \mathrm{O}_{2}$ to the liquid phase. Table $\mathrm{S} 3$ displays the informations gathers from the work of Gorbanev et al. in the first row. The authors observed an increase of $1.5010^{-3} \mathrm{M}\left(\mathbf{M}\right.$ is the symbol for $\left.\mathbf{m o l ~} \mathbf{L}^{-1}\right)$ for $\mathrm{H}_{2} \mathrm{O}_{2}$ and $23.5010^{-6} \mathrm{M}$ for radical-OH. As such increase were observed after 60 second under toch-like interaction, such value is divided by 60 second in the second row.

Based on the work of Gonçalves et al. (4), the acidification rate is $293.34 \times 10^{-}$ $12 \mathrm{~mol} \mathrm{~s}^{-1}$. The release rate is obtained dividing this value by the volume of the nanoreactor from table S2. Table S4 displays the results.

Based on the work of Liu et al. (5), the anodic plasma promotes a liquid uptake of $\mathrm{H}_{2} \mathrm{O}_{2}$ equal to 1200 micro-mol per hour. After converting micro mol to mol and hour to seconds, $20,000.0 \times 10^{-9} \mathrm{~mol} \mathrm{~s}^{-1}$ is found. Table S5 displays the results of this procedure.

Table S3: Radical-like scavengers rate of liquid uptake by torch-like interaction (source terms of scavenger).

\begin{tabular}{|c|c|c|c|}
\hline & Scavengers (S) detectable in liquid phase $\rightarrow$ & $\begin{array}{r}\text { Hydrogen } \\
\text { peroxide }\left(\mathrm{H}_{2} \mathrm{O}_{2}\right)\end{array}$ & $\begin{array}{r}\text { Hydroxide Radical } \\
\left(\mathrm{OH}^{*}\right)\end{array}$ \\
\hline $\begin{array}{l}\text { Data from } \\
\text { Gorbanev et al. } \\
\text { 2015.(3) }\end{array}$ & $\begin{array}{l}\text { Detectable amount on the electrolyte after } \\
60 \text { second under contact with torch-like } \\
\text { plasma } \\
\text { (1st-row) }\end{array}$ & $1.5010^{-3} \mathrm{M}$ & $23.5010^{-6} \mathrm{M}$ \\
\hline $\begin{array}{l}\text { Estimations from } \\
\text { This work based } \\
\text { on data from } \\
\text { Gorbanev et al. } \\
\text { 2015. (3) }\end{array}$ & $\begin{array}{c}\text { Rate of specie uptake by the liquid } \\
\frac{1}{V} \times \boldsymbol{q}_{S} \\
\text { (line } 1 \text { divided by } 60) \\
\text { (2sd-row) }\end{array}$ & $\begin{array}{r}25.0010^{-6} \mathrm{~mol} \\
\mathrm{~L}^{-1} \mathrm{~s}^{-1}\end{array}$ & $0.3910^{-6} \mathrm{~mol} \mathrm{~L}^{-1} \mathrm{~s}^{-1}$ \\
\hline
\end{tabular}


Table S4: Release rate of the Birkeland-Eyde products (source terms of scavenger).

\begin{tabular}{|c|r|r|r|}
\hline $\begin{array}{c}\text { Data from Gonçalves } \\
\text { et al. 2019.(4) }\end{array}$ & $q_{N O 3}=q_{H+}$ & $293.34 \times 10^{-12}$ & $\mathrm{~mol} \mathrm{~s}^{-1}$ \\
\hline $\begin{array}{c}\text { Estimations from This } \\
\text { work based on data } \\
\text { from Gorbanev et al. } \\
\text { 2015. (4) }\end{array}$ & $\begin{array}{c}\text { Rate of specie uptake by the liquid } \\
\mathbf{1}\end{array} \times q_{N O 3}=\frac{\mathbf{1}}{\boldsymbol{V}} \times q_{H+}$ & $12.43 \times 10^{-2}$ & $\mathrm{~mol} \mathrm{~L}^{-1} \mathrm{~s}^{-1}$ \\
\hline
\end{tabular}

Table S5: Radical-like scavengers rate of liquid uptake by action of anodic discharge (source terms of scavenger).

\begin{tabular}{|c|c|c|c|}
\hline $\begin{array}{l}\text { Data from from } \\
\text { Liu et al. 2016.(5) }\end{array}$ & $q_{\mathrm{OH}}$ & $20,000.0 \times 10^{-9}$ & $\mathrm{~mol} \mathrm{~s}^{-1}$ \\
\hline \begin{tabular}{|} 
Estimations from \\
This work based \\
on data from \\
from Liu et al. \\
$2016 .(5)$
\end{tabular} & $\begin{array}{l}\text { Rate of specie uptake by the liquid } \\
\qquad \frac{\mathbf{1}}{\boldsymbol{V}} \times q_{\mathrm{OH}}\end{array}$ & $8,470.00 \times 10^{0}$ & $\mathrm{~mol} \mathrm{~L}^{-1} \mathrm{~s}^{-1}$ \\
\hline
\end{tabular}

This work adheres to recent suggestion that only radical $\bullet \mathrm{OH}$ is effectively solvated by the liquid, being $\mathrm{H}_{2} \mathrm{O}_{2}$ locally formed (6) into the nano-reactor by the reaction 33 from the article. For this reason, the release rate of $\mathrm{H}_{2} \mathrm{O}_{2}$ under anodic discharge is considered the release rate of radical $\bullet \mathrm{OH}$ in table $\mathrm{S} 5$. In table 1 of the article, the term $\boldsymbol{q}_{\boldsymbol{O}}$ for torch-like is assumed to be the sum of $\boldsymbol{q}_{\mathrm{H2O}}$ plus $\boldsymbol{q}_{\mathrm{OH}}$, thus it equals to $25.3910^{-6} \mathrm{~mol} \mathrm{~L}^{-1} \mathrm{~s}^{-1}$. All $\mathrm{H}_{2} \mathrm{O}_{2}$ absorbed by the liquid had already entered the solutions in the form of radical $\bullet \mathrm{OH}$. Note that this is an underestimations of the release rate of radical $\bullet \mathrm{OH}$ once not all radical $\bullet \mathrm{OH}$ is converted to $\mathrm{H}_{2} \mathrm{O}_{2}$ but some scavengers the hydrated electrons.

\section{References}

(1) K. Urabe, N. Shirai, K. Tomita, T. Akiyama, and T. Murakami, "Diagnostics of atmospheric-pressure pulsed-dc discharge with metal and liquid anodes by multiple laser-aided methods," Plasma Sources Sci. Technol., vol. 25, no. 4, 2016.

(2) P. Rumbach, D. M. Bartels, R. M. Sankaran, and D. B. Go, "The solvation of electrons by an atmospheric-pressure plasma," Nat. Commun., vol. 6, pp. 1-6, 2015 . 
(3)Y. Gorbanev, D. O'Connell, and V. Chechik, "Non-Thermal Plasma in Contact with Water: The Origin of Species," Chem. - A Eur. J., vol. 22, no. 10, pp. 34963505, 2016.

(4) Gonçalves I A, Barauna J, Cunha-Filho F J, et al. "Reduction of Aqueous Ag+ steered by electrochemical plasma: Connecting the Bulk pH Variation with the Reaction Pathways for Hydrated Electrons" J.Braz. Chem. Soc., 30, 1252, 2019.

(5) J. Liu, B. He, Q. Chen, J. Li, Q. Xiong, G. Yue, X. Zhang, S. Yang, H. Liu, Q.H. Liu, "Direct synthesis of hydrogen peroxide from plasma-water interactions", Sci. Rep., 6, 38454, 2016.

(6) R. Paul, M.B. David, B.G. David, The penetration and concentration of solvated electrons and hydroxyl radicals at a plasma-liquid interface, Plasma Sources Sci. Technol., 27 , 115013, 2018. 